\title{
Research on Species Composition and Flora of Invasive Plants in Changchun Area
}

\author{
Tongbao Qu ${ }^{1, a}$ Fanyong Meng ${ }^{1, b}$ \\ ${ }^{1}$ Jilin Agricultural University, Changchun, Jilin, China, 130118 \\ aemail,419730800@qq.com, bemail,914270168@qq.com
}

Keywords: Changchun Area, Invasive Plants, Species Composition, Plants Flora

\begin{abstract}
In this paper, the species and floristic composition of invasive plants in Changchun area were studied. There are 85 species of invasive plants in Changchun, belonging to 26 families and 64 genera. Compositae, Amaranthaceae, Gramineae, Leguminosae and Solanaceae constitute the main body of invasive plants, among which 18 species Compositae $(21.18 \%)$ are the most. The invasive plants which native to Europe and North America accounted for $42.35 \%$ and $38.82 \%$, indicating that plants from these areas more invasive. There were 81 species $(95.29 \%)$ of the exotic herbs, which indicated that the herbaceous plants were more invasive to Changchun area. The results of floristic analysis showed that the types of invaded flora in Changchun were mainly distributed in the world, followed by tropical and northern temperate. The distribution types of invaded genera were dominated by the distribution of the world, with temperate regions of Asia, Mediterranean and West Asia Asian and Central Asian distribution.
\end{abstract}

\section{Introduction}

Biological stability of the ecological balance system, when a species of exotic plants in the establishment of the population growth and reproduction process of the original habitat plants have an impact, change or threaten the biological diversity of the region, the formation of invasive organisms (Zhang Guoliang , 2008; He Jiaqing, 2012). Invasive plants endanger the biodiversity of native populations, causing the biota to lose its uniqueness in the composition and function of the genetic species, leading to biological homogeneity (Wang, 2009; Li B, 2009). A large number of green ornamental plants and economic plants in the introduction of the disorder has undoubtedly increased the risk of alien plant invasion (Zheng Baojiang, 2012).

The invasion and invasiveness of alien species, the invasiveness of invasive species and biological invasion, and the management and management of invasive species have become the main research directions (Pimentel et al., 2009) Al., 1984; Xu Ru-mei and Ye Wan-hui, 2003). China; 2.Institute of Botany, Chinese Academy of Sciences, Beijing 100080, China) The research on alien invasive plants in northeast China has made some achievements (Sun Cang, 2007; Li Bin et al., 2007; Catalog of Invasive Plant Cataloging and Its Flora Composition.

\section{General Survey of Changchun Area}

Changchun is located at latitude $43^{\circ} 05^{\prime}-4^{\circ} 15^{\prime}$ north latitude, $124^{\circ} 18$ '-12702' east longitude, in the hinterland of Songliao Plain in northeastern China on the east coast of Eurasia, the elevation of 250-350 meters, (About 9\%), terraces (about 41\%), and plains (about 50\%). The landform consists of mountains, plains and open terraces with a slope of 4 to 5 degrees and a width of 20,604 square kilometers. Changchun area is a continental monsoon climate zone, located in the transition zone of the humid area to the sub-arid zone, the temperature increases from east to west, precipitation descends from east to west, with four seasons, rain and hot season, dry and wet moderate climate characteristics. Changchun area traffic is very developed, for the invasion and spread of exotic plants to provide a convenient condition. 


\section{Research Methods}

Using the route survey and focus on the investigation of a combination of ways to investigate. The species composition of invasive plants in Changchun was determined by using the data of Chinese invasive alien species. The species composition of the invasive plants in Changchun was determined by field investigation, and the distribution system of the world seed plant families and genera classified by Wu Zhengyi (1991, 2003).

\section{Results and Analysis}

The Species Composition of Invasive Plants in Changchun Area. A total of 1450 plant specimens were collected and 85 species of alien invasive plants were identified. They belonged to 26 families and 64 genera. Among them, dicotyledonous plants belonged to 23 families and 53 genera and 74 species. The monocotyledons had only 10 genera, 2 families, 10 genera and 1 ferns Division 1 genera 1 species. Among them, there were 18 species of Asteraceae, which accounted for 21.18\% of the total species of invasive plants. There were 9 species of Amaranthaceae and 9 species of Gramineae, accounting for $10.59 \%$ of the total. 9.41\%, Solanaceae 7 species, accounting for 8.24\%; Convolvulaceae 5 species, accounting for 5.88\%; Caryophyllaceae 4 species, accounting for 4.71\%; 3 families have 2, including cruciferae and car front, each $3.53 \%$; 2 species of the family has 3, Lithospermaceae, Chenopodiaceae, Malvaceae, each 2.35\%; 1 species of 13 families, including Equisetaceae, Lacertaceae, Impatiens, Cyperaceae, Flax, Sangke, Willow Division, Poppy Branch, Polygonaceae, Umbelliferae, Grape Branch, Viola Division, each 1.18\%.

The invasive plants originated in Europe and North America accounted for 36 and 33 species respectively, accounting for $42.35 \%$ and $38.82 \%$ of the total respectively. It indicates that plants from European and North American origin are more likely to be invasive plants in Changchun area. Which were included in China's entry list of plant quarantine pests there are four, namely: ragweed, three-leaf ragweed, venom and wild oats.

From the life-type point of view, there are 81 kinds of herbs, accounting for $95.29 \%$ of the total, is the main alien invasive plants. There were 59 species $(69.41 \%)$ of perennial herbaceous plants and 19 species $(22.35 \%)$ of perennial herbaceous plants. Three $(3.53 \%)$ of the three herbaceous plants (3.53\%) had shorter plant life history, higher seed mass and faster proliferation. The biennial or perennial plants Underground tuberous root or rhizome, asexual reproduction ability is very strong. These biological characteristics of invasive herbaceous plants have seriously harmed the ecology and economy of Changchun. The invasion of woody plants only 4 species, accounting for $4.71 \%$, of which 1 species of wood vines, accounting for $1.18 \%$.

Floristic Study of Invasive Plants in Changchun Area. The Changchun area belongs to the Pan-Arctic flora and the sub-region of the Eurasian steppe in the Mongolian steppe region. The plant flora is relatively young and is in the forest and desert transition area. In the east and southeast, And the desert is intertwined with each other, and it is at the intersection of Asia desert plant sub-region and Qinghai-Tibet Plateau plant sub-region, thus forming its unique flora characteristics.

There are 26 families of invasive plants in Changchun area, belonging to the world distribution, tropical distribution and northern temperate zone (Table 1). The distribution of the world is the main body of the invasive species, with 19 families accounting for $73.08 \%$. Followed by tropical distribution, there are 5 families, accounting for 19.23\%; North temperate distribution is very small, only 2 families, accounting for $7.69 \%$. According to the distribution types of the flora in Changchun area, the invasion of the World Division is very common, accounting for $30.16 \%$ of the total number of branches in the whole country, while the tropical distribution and the North Temperate and the South Temperate are distributed in the whole temperate zone, $5.95 \%$ and $3.51 \%$, respectively. 
Table 1 Areal-types of family of invasive plants in Changchun

\begin{tabular}{llll}
\hline Areal Types & $\begin{array}{l}\text { Number } \\
\text { Of Family }\end{array}$ & $\begin{array}{c}\text { Porportion } \\
(\%)\end{array}$ & $\begin{array}{l}\text { Total Family } \\
\text { in China }\end{array}$ \\
\hline 1. Cosmopolitan & 19 & 73.08 & 63 \\
2. Pantropic & 5 & 19.23 & 84 \\
8-4. N.Temp. \& S. Temp. disjuncted. ("Pan-temperate") & 2 & 7.69 & 57 \\
Total & 26 & 100 & 164 \\
\hline
\end{tabular}

There are 64 genera of invasive plants in Changchun area, belonging to 9 distribution types and 3 variants (Table 2). Overall, the distribution of the world is $28.13 \%$ of the invasive plants, 18 genera and 33 genera, Followed by the temperate zone of temperate zone in Asia, Mediterranean, West Asia, Central Asia and Central Asia. The distribution of temperate zone in temperate zone is only 25\%. There are 18 genera in 16 genera, 20.31\% in pantropical distribution, 10.94\% 1 genera and 1 species, accounting for only $1.56 \%$. The distribution of invasive species in the world is the most, followed by the northern temperate zone and the pantropical zone, which account for $73.44 \%$.

Table 2 Areal-types of genus of invasive plants in Changchun

\begin{tabular}{|c|c|c|c|}
\hline Areal types & $\begin{array}{l}\text { Number Of } \\
\text { Genera in } \\
\text { Changchun }\end{array}$ & $\begin{array}{l}\text { Porportion } \\
(\%)\end{array}$ & $\begin{array}{l}\text { Total } \\
\text { Genera in } \\
\text { China }\end{array}$ \\
\hline 1. Cosmopolitan & 18 & 28.13 & 104 \\
\hline 2. Pantropic & 13 & 20.31 & 316 \\
\hline $\begin{array}{l}\text { 3.Tropical Asia and Tropical America } \\
\text { disjuncted }\end{array}$ & 3 & 4.69 & 62 \\
\hline 8. North Temperate & 11 & 17.19 & 213 \\
\hline $\begin{array}{l}\text { N.Temp. \& S. Temp. disjuncted. } \\
\text { ("Pan-temperate") }\end{array}$ & 5 & 7.81 & 57 \\
\hline $\begin{array}{l}\text { 9. East Asia and North America } \\
\text { disjuncted }\end{array}$ & 4 & 6.25 & 123 \\
\hline 10. Old World Temperate & 4 & 6.25 & 114 \\
\hline $\begin{array}{l}\text { 10-1.Mediterranea.W. Asia (or C. } \\
\text { Asia) \& E. Asia disjuncted. }\end{array}$ & 1 & 1.56 & 25 \\
\hline $\begin{array}{l}\text { 10-3.Eurasia\&S. Africa (Sometimes } \\
\text { also Australasia) disjuncted. }\end{array}$ & 2 & 3.13 & 17 \\
\hline 11. Temperate Asia & 1 & 1.56 & 55 \\
\hline $\begin{array}{l}\text { 12. Mediterranean, West Asia to Central } \\
\text { Asia }\end{array}$ & 1 & 1.56 & 152 \\
\hline 13. Central Asia & 1 & 1.56 & 69 \\
\hline Total & 64 & 100 & 1208 \\
\hline
\end{tabular}

Overall, the distribution of invasive plants in Changchun region is 18 , accounting for $28.13 \%$. The distribution of the world constitutes the main body of invasive species, followed by the Pan-tropical distribution is 13, accounting for 20.31\%. Mediterranean region, West Asia to Central Asia distribution and distribution of Central Asia is the least, only 1 genus, accounting for $1.56 \%$. It indicates that the distribution of invasive plants in Changchun area has wide distribution and regional characteristics, and better reflects the climate characteristics of the Northeast Plains subfacies in the Mongolian steppe region of the Eurasian steppe plant area in the Pan-Arctic flora of Changchun area.

\section{Conclusion and Discussion}

The distribution pattern of invasive plants is the result of the interaction of environmental factors and human activities (Rose, 2004), while human activities are the main factors influencing the 
distribution and spread of invasive species (Chen, 2009). Changchun area is located in the transitional zone between plain and mountain area. It has a special geographical position, and the human activities such as long-term reclamation and grazing have a profound influence on the community structure and distribution of Changchun area ecosystem. The process of vegetation restoration in the landscaping may also bring favorable conditions for the growth of invasive species, which leads to the particularity of the invasive plants distribution in Changchun area.

The invasive plants in Changchun area were dominated by Asteraceae and those originated from Europe and North America. It has something to do with Asteraceae's superior reproductive capacity and adaptability. The most distribution of invasive plants in Changchun area is from Europe, which reflects the characteristics of the flora of the Eurasian steppe sub-region and the northeastern plain region of the Mongolian steppe region, which is consistent with the geographical position and climate of this region.

Biological invasions are transforming the natural environment and ecological characteristics of the world at an unprecedented rate, and the ecosystem on which humans depend for survival will face the risk of depletion and loss of diversification if it fails to take effective measures to prevent it (Mack 2000). The results of this paper hope to provide the theoretical basis for plant diversity conservation and ecosystem stability in Changchun.

\section{References}

[1] Brandt K. Invasive Alien Species and the Global Invasive Species Programme[J]. Phycological Society of Southern Africa Newsletter, 2003, 54: 7-19.

[2] Chen Z W, Yang J P, Wang R Z, Shang H W. Spatial distribution pattern of Solidago canadensis in Zhejiang Province and its relationship with anthropogenic activities[J]. Acta Ecologica Sinica, 2009, 29( 1) : 120-129.

[3] Li B, Li Y Y. The interaction between invasive and native species in the biological invasion[J]. Sichuan Environment, 2009, 28 (1) : 64 -67

[4] Mack Richard N, Simberloff Daniel, Lonsdale W Mark, et al. Biotic invasions: causes, epidemiology,global consequences, control[J]. Ecological Applications, 2000, 10(3): 689-710.

[5] Pimentel D, Glenister C, Fast S, Gallahan D. Environ-mental risks of biological pest controls[J]. Oikos, 1984, 42, 283-290.

[6] Rose M, Hermanutz L. Are boreal ecosystems susceptible to alienplant invasion? Evidence from protected areas[J]. Oecologia, 2004, 139(3): 467-477.

[7] Wang G M, Yang J C, Jiang C D, Zhao H T, Zhang Z D. A literature review on biotic homogenization[J]. Biodiversity Science, 2009, 17 (2): 117-126. 